\title{
Los estudios de la represión, discusiones y agendas de investigación actuales
}

Reseña de: Gabriela Águila, Santiago Garaño y Pablo Scatizza (coords.). La represión como política de Estado. Estudios sobre la violencia estatal en el siglo XX, Buenos Aires, Imago Mundi, 2020.

\author{
Carlos Fernando López de la Torre \\ carloslopezdelatorre@filos.unam.mx \\ Colegio de Estudios Latinoamericanos. Universidad \\ Nacional Autónoma de México, México
}

Cita sugerida: López de la Torre, C. F. (2021). Los estudios de la represión, discusiones y agendas de investigación actuales [Revisión del libro La represión como política de Estado. Estudios sobre la violencia estatal en el siglo XX por G. Águila, S. Garaño y P. Scatizza (coords.)]. Sociohistórica, 48, e154. https://doi.org/10.24215/18521606e154

La represión como politica de Estado. Estudios sobre la violencia estatal en el siglo XX es el emprendimiento editorial más reciente de la Red de Estudios sobre Represión y Violencia Política (RER), fundada en 2014 con el propósito de crear un espacio de reunión y de debate que contribuyera a la conformación de un novedoso campo de estudios en el mundo académico. En tal sentido, esta obra y su contenido testifican los fructíferos avances desarrollados en los últimos años, con una red de investigadores en crecimiento y un campo de estudios que, además de consolidado, goza de innovaciones constantes en los enfoques de interpretación, propuestas analíticas y temas, los cuales han sido formulados en distintas escalas y contextos que superan el ámbito de la historia reciente argentina. 
El libro está compuesto por una selección de trabajos que fueron presentados en el III Coloquio Internacional de Violencia Política en el Siglo XX y en las IV Jornadas de la RER (2019). De acuerdo a los coordinadores de la publicación, Gabriela Águila, Santiago Garaño y Pablo Scatizza, ambos encuentros revistieron singular relevancia por su poder de convocatoria internacional y tanto por las múltiples experiencias como por los períodos históricos abordados en las mesas de discusión. Por tanto, la obra constituye un gran aporte al ilustrar lo que se está discutiendo actualmente en los estudios sobre la represión en la Argentina, junto a la incorporación de investigaciones sobre otros países latinoamericanos, lo que brinda la posibilidad de contrapuntear las experiencias nacionales en clave regional y transnacional.

La estructura del libro se divide en tres secciones, que abordan ejes o problemáticas cruciales para los estudios de la represión. En la primera sección se reúnen cinco trabajos sobre la violencia estatal en la Argentina y el Cono Sur en distintas temporalidades del siglo XX. Las contribuciones tienen en común la preocupación de analizar la violencia y los dispositivos represivos estatales en procesos históricos de mediana y/o larga duración, problematizando en torno a las continuidades y rupturas en las formas de represión legalizadas, la articulación de lo legal con lo ilegal y la persistencia hasta la actualidad de expresiones violentas que fomentan la criminalización de sujetos históricamente estigmatizados y vilipendiados. En síntesis, son trabajos que buscan explicar tendencias represivas, su evolución histórica y sus posibles incidencias en el presente.

La primera sección se abre con el trabajo de Marina Franco y Ernesto Bohoslavsky, quienes invitan a pensar la violencia estatal en el siglo XX argentino como un problema de larga duración, que encierra elementos estructurales y especificidades de época que es necesario dilucidar para su comprensión. Lejos de ofrecer respuestas definitivas, los autores proponen algunos temas y planteamientos metodológicos para abordar la cuestión, destacando el manejo de las escalas de análisis y la construcción de nuevas periodizaciones, basadas más en las violencias de Estado a trabajar que en los recortes institucionales tradicionales, con la finalidad de observar las continuidades y transformaciones de las violencias más allá de la naturaleza del régimen de turno.

Walter Delrio y Pilar Pérez analizan la represión sobre los pueblos indígenas, una de las violencias estructurales intrínsecas a la construcción de la Argentina moderna, a partir del estudio de los campos de concentración en la Norpatagonia y su conformación en el contexto de las campañas militares de conquista de fines del siglo XIX. Manejando una periodización de mediana duración, que va de 1870/1880 a 1940, los autores muestran cómo los campos fueron el dispositivo represivo que configuró un nuevo paradigma de territorialización impuesto por el Estado argentino, el cual implicó el aniquilamiento y reorganización de las estructuras sociales de los pueblos originarios. Prueba de ello fueron las violencias que giraron en torno a los campos (despojo de bienes, desarraigo del núcleo familiar), al igual que los estereotipos construidos en torno a los indígenas, que han perdurado y funcionado como incentivo a la represión de los conflictos territoriales del presente.

Por su parte, Verónica Valdivia Ortiz de Zárate recorre la historia de Chile en los siglos XX y XXI desde la relación entre represión estatal y conflicto político. La perspectiva de larga duración le permite desmontar la imagen de un país democrático y estable, fundado en el acuerdo, para sostener que la dificultad de generar consensos posibilitó los conflictos y la respuesta estatal a través de distintos dispositivos, como la fuerza policial o militar y la legislación de seguridad interna. La historiadora muestra las continuidades en las formas represivas, a la par que destaca el quiebre que significó la dictadura de Augusto Pinochet, que impulsó un aparato represivo planificado y con voluntad de exterminar a los opositores. Asimismo, sus reflexiones sobre el período posdictatorial aportan elementos para comprender los episodios de represión en fechas recientes, violencia circunscripta a un paradigma de seguridad ciudadana que criminaliza toda protesta anti-neoliberal y que tiene uno de sus principales resortes en la policía militarizada de Carabineros.

Rodrigo Patto Sá Motta aborda la violencia política en el Brasil de la segunda mitad del siglo XX, desde el ámbito legal y los aparatos represivos estatales, con la intención de distinguir los rasgos diferenciados entre el interregno "democrático" (1945-1964) y la dictadura militar (1964-1985). Acto seguido, el historiador 
identifica las características estructurales de la violencia practicada por el Estado brasileño, entre ellas el sostenimiento de la desigualdad social, el clasismo y el arraigo del anticomunismo como discurso contrario a toda apuesta por el cambio social.

Valeria Manzano indaga en un tema novedoso para los estudios de la historia reciente argentina: la legislación y las políticas represivas en torno a las drogas. Tomando como hilo conductor la sanción y aplicación de la ley 20771 -la "ley de drogas"- entre 1974 y 1989, la autora atiende a los paradigmas sobre los que se construyó el "problema" de la droga, los usos punitivos de la ley, las representaciones de los consumidores y las críticas limitadas que hubo en la "primavera" alfonsinista hacia dicha reglamentación, para formular una historia de las políticas de drogas que, durante el período trabajado, atravesó un arco políticocultural de corte autoritario en el que la "droga" y sus usuarios fueron concebidos como enemigos públicos, primero en clave de la "seguridad nacional” y después como un problema de salud pública, sumado al hecho de que la legislación fue instrumentada para la persecución y hostigamiento de una juventud asociada con la rebeldía, el vicio y la "subversión".

La segunda sección del libro reúne seis estudios sobre la represión y la violencia política en la historia reciente argentina, en la cual convergen reflexiones teórico-conceptuales y análisis empíricos de casos concretos. Gabriela Águila debate en torno a los conceptos que usamos al tratar fenómenos de represión; específicamente, si la noción de "violencia política" es adecuada para categorizar la violencia de la última dictadura militar. La propuesta de la autora consiste en complejizar los conceptos genéricos al ponerlos a prueba con los hechos historiados, lo que permitirá observar su potencial y limitaciones al momento de describirlos. Tal metodología revela que los objetivos inmediatos y la producción de violencia por las fuerzas de la dictadura poseían sentidos políticos (el aniquilamiento de la "subversión”); sin embargo, éstos se vieron desbordados cuando la ejecución de la violencia se articuló con estrategias de control social, no necesariamente violentas físicamente, en la búsqueda de disciplinar a la población. Por ende, el concepto de "violencia política" es oportuno, aunque limitado, y es más adecuado "violencia estatal" o "represión”, pues permite identificar el tipo de violencia y sus perpetradores.

Luciano Alonso trabaja la "transición a la democracia" en los ochenta -período todavía en discusión respecto de sus límites temporales- desde la propuesta de analizar cómo la violencia política afectó el plano emocional de la sociedad argentina y articuló con él. Para el autor, pensar las distintas formas de violencia implica rescatar no sólo las muestras de fuerza física, sino también las acciones que, sin incurrir al uso explícito de la fuerza, son sentidas como violentas y afectan la subjetividad de sus potenciales víctimas. Esta interpretación plantea el potencial analítico del estudio de las sensibilidades y su papel en el sustento o transformación de los regímenes políticos que, en el caso del período transicional, significó un cambio emocional colectivo frente a la violencia estatal y el poder militar en declive. En dicho cambio, los impactos emocionales de procesos como el "show del horror" y el cuestionamiento a la violencia extrema incidieron en el descrédito de la violencia revolucionaria y el apoyo a la institucionalidad democrática (con la tolerancia a ciertas prácticas violentas estatales).

El trabajo de Santiago Garaño indaga en el Operativo Independencia y la dimensión afectiva de la experiencia vivida por los militares en el teatro de operaciones. Garaño ofrece una mirada novedosa de aquella experiencia represiva considerada "laboratorio" del terror estatal de la última dictadura, al atender a las estructuras de sentimiento que configuraron una atmósfera colectiva propensa al ejercicio de la represión. A través de los relatos de los perpetradores partícipes de la campaña militar, el autor muestra el coctel de emociones que alimentaron un espíritu de camaradería y venganza por los "compañeros caídos" ante la guerrilla, que logró comprometer a los soldados en la acción punitiva, independientemente de su ilegalidad. En tal sentido, el Operativo Independencia puede ser visto como una experiencia afectiva disruptiva, en la cual el duelo y los traumas causados por el combate fueron resignificados, a la par de explotados por la superioridad castrense, lo que hizo posible la composición de un nuevo cuerpo represivo masculinizado en clave "antisubversiva". 
Pablo Scatizza y Rodrigo González Tizón trabajan la detención clandestina durante la última dictadura militar. Su punto de arranque es la discusión con un sentido común que consagró los centros clandestinos de detención (CCD) como el dispositivo represivo por excelencia del régimen militar; lectura acompañada tanto por la noción de que tales entidades fueron estáticas en el tiempo, como por la obliteración de otros recursos involucrados en la desaparición de personas. Manejando una metodología basada en el análisis diacrónico y el cambio de escalas, los autores complejizan en torno a las dinámicas y actores partícipes en la detención clandestina, rescatando matices y especificidades en su funcionamiento. Por ejemplo, se destaca el papel de los centros de detención clandestina (CDC), espacios de reclusión transitoria y elaboración de información, por lo general en manos de fuerzas de seguridad no militares, que crecieron en importancia conforme la ejecución de la represión se alejaba de las grandes manchas urbanas, patrón que matiza la tesis concentracionaria y su aplicabilidad en todo el país. A su vez, Scatizza y González Tizón proponen la historización de la detención clandestina, con el fin de rendir cuenta de la evolución de los centros clandestinos y sus lógicas represivas, cuestión que ilustran a partir del análisis de casos concretos.

El siguiente artículo pertenece a Mario Ranalletti, quien se interroga sobre los factores que posibilitaron la violencia extrema de la última dictadura militar. Para el autor, la voluntad de aniquilar y la crueldad no fueron cuestiones prefijadas en la planificación represiva de la dictadura, sino resultado del adoctrinamiento político-moral que los perpetradores recibieron desde mediados del siglo XX, el cual configuró un imaginario regulado por la convicción de que la matanza del "enemigo interno" era necesaria e inevitable para la salvación de la nación. Aunado al factor doctrinal, Ranalletti sugiere que esa violencia extrema pudo desarrollarse gracias a la autonomización operativa de los comandos ejecutores de la represión clandestina, cuya morfología espontánea e intuitiva supuso la erosión del control jerárquico sobre estos grupos y la ejecución de operativos con total libertad.

La sección se cierra con un artículo de Cora Gamarnik, en el que analiza la relación entre dictadura, medios y fotografía a partir de la foto del "falso abrazo" entre un policía y una madre de Plaza de Mayo en 1982, imagen ampliamente publicitada, al punto de convertirse en una de las más emblemáticas del período transicional. La autora narra la historia de la fotografía y las inmediatas operaciones discursivas, usos y manipulaciones políticas y mediáticas de las que fue objeto, prestando especial atención a las formas en como contribuyó a la construcción de una narrativa sobre la "reconciliación", noción ambigua y en pugna de sentidos que discurría, según el enunciante, entre la impunidad, el cierre del pasado, la aceptación de la amnistía castrense y el olvido.

Uno de los objetivos de la RER es pensar el caso argentino a la luz de otras experiencias regionales o internacionales, a través de perspectivas comparadas o transnacionales. La tercera sección del libro muestra dicho interés, al reunir cinco trabajos dedicados al estudio de redes, conexiones e intercambios entre regímenes y actores represivos de América Latina y otras regiones del mundo, y de aquellos colectivos u organizaciones que desde el exilio promocionaron el activismo internacional por los derechos humanos. Además, estos trabajos -incluso sin proponérselo- pueden ser ubicados dentro de las corrientes historiográficas que estudian la Guerra Fría desde el "sur global”, al rescatar a los "actores periféricos", sus intereses e incidencias en un escenario internacional atravesado por el conflicto bipolar.

La última parte del libro se inicia con un trabajo de Silvina Jensen, en el que estudia el activismo exiliar y sus derroteros en la denuncia internacional de los crímenes de la dictadura. La historiadora atiende a la historicidad de la denuncia para formular que el activismo atravesó dos fases entre 1976 y 1981, identificables por el enfoque adoptado por los exiliados. Así, mientras la primera fase (1976-1979) se caracterizó por el esfuerzo de instalar la "cuestión" de la represión argentina en el espacio público internacional desde la narrativa de los derechos humanos, la segunda (1979-1981) correspondió al deslizamiento de la denuncia hacia el "problema de los desaparecidos", enfoque cuya apuesta fue visibilizar este delito como el crimen más aberrante del régimen militar. Ante los desafíos para alcanzar estos objetivos, los exiliados recurrieron a un ingenioso repertorio de estrategias que la autora esquematiza hábilmente y que permitieron, en conjunción 
con las redes y foros de solidaridad en distintas geografías, la construcción de un discurso signado por la convicción de que los crímenes de la dictadura eran violatorios del derecho internacional humanitario y, por tanto, el sistema represivo acreditaba el calificativo de "terrorismo de Estado".

En sintonía con el trabajo de Jensen, Hernán Confino aborda el exilio montonero y la denuncia de las violaciones a los derechos humanos. El objetivo del autor es realizar un acercamiento a las redes políticas que tejieron los militantes montoneros en el exterior y analizar cómo el exilio modificó los repertorios políticoorganizativos de la organización, además de expandir su radio de acción en clave transnacional, al incorporar la denuncia humanitaria en su habitus militante. El trabajo da cuenta de la compleja experiencia exiliar montonera, de circuitos de denuncia y de las tensiones que produjo la conducción al pretender subordinar la denuncia humanitaria a una estrategia político-militar, lo que generó conflictos entre los militantes, cuyo activismo excedió los intereses de la conducción o estos se yuxtapusieron con los de los organismos humanitarios donde participaron. Confino contribuye a una mayor comprensión de Montoneros en sus años finales y, opuesto a viejas interpretaciones que hacían una separación taxativa entre los derechos humanos y la militancia revolucionaria, pone de manifiesto que estas luchas coexistieron e interconectaron en el exilio.

Mariana Joffily y Maud Chirio formulan un acercamiento a las circulaciones transnacionales de los represores brasileños durante la Guerra Fría, rescatando sus áreas de desarrollo: la profesionalización castrense en el exterior, los cursos de instrucción contrainsurgente en academias brasileñas y extranjeras, y las asesorías de los agregados militares en los países vecinos del Cono Sur. Es un trabajo que muestra la ambición brasileña por ser una pieza clave en la represión regional, aprovechando una doctrina de seguridad nacional madura, la creación de sus propias instituciones de enseñanza en la "guerra antisubversiva" y la transmisión de conocimientos en materia de inteligencia a sus pares latinoamericanos.

Por su parte, Julieta Rostica presenta una síntesis de sus investigaciones previas sobre la coordinación represiva entre la Argentina y varios países de Centroamérica. La socióloga sostiene que a partir de 1980 hubo un crecimiento, si bien no numeroso, en la presencia de militares argentinos en América Central, producto de dos motivaciones: la hipótesis de la amenaza de una "centroamericanización" de la lucha revolucionaria tras el triunfo del sandinismo y la política estadounidense en la administración de Jimmy Carter, la cual empujó a una mayor colaboración represiva entre los Estados de la región. El resultado de esta proximidad fue una transnacionalización en las formas de represión que, sugiere Rostica, puede constatarse en el modus operandi detención ilegal-tortura-desaparición forzada que primó en ambientes urbanos de la Argentina, Honduras, Guatemala y El Salvador; si bien es oportuno señalar que tales prácticas no fueron exclusivas de los argentinos, por lo que su aplicación en otros contextos no implicó, necesariamente, la intermediación conosureña.

Por último, Marisa Pineau presenta un interesante trabajo sobre las relaciones entre la Argentina y la Sudáfrica del apartheid en las décadas de 1960 y 1970, argumentando que ambas naciones forjaron un vínculo peculiar desde la confraternidad ideológica de percibirse eslabones secundarios, pero necesarios, en la defensa del mundo occidental y cristiano. Esta vinculación se tradujo en dos ejes atravesados por la cuestión militar y de seguridad hemisférica: el proyecto fallido de la Organización del Tratado del Atlántico Sur (OTAS) y la diplomacia a nivel de las Armadas entre ambos países. La autora no sólo recupera estos lazos sino que también reflexiona en torno a sus límites, constatables cuando el gobierno de Pretoria se negó a dar refugio a represores como Alfredo Astiz en 1982, hecho sintomático de que los encuentros ideológicos y militares no fueron suficientes ante los cambios de época.

En suma, La represión como politica de Estado. Estudios sobre la violencia estatal en el siglo XX es una obra colectiva de la RER que presume el estado actual de las investigaciones teóricas y empíricas de la violencia y la represión en la Argentina, sumado a la apertura de diálogo y encuentro con perspectivas procedentes de otros países. En general, los trabajos manejan propuestas de análisis interesantes por su desprendimiento de sentidos comunes y lecturas tradicionales, los novedosos interrogantes que plantean y las respuestas que, lejos de significar un cierre, invitan a la reflexión continua. Si bien resulta una obviedad decirlo, el libro no agota las variadas líneas de investigación que hay alrededor de la violencia estatal, y es más bien una muestra acotada 
por cuestiones de espacio y selección temática. Sin embargo, tal cuestión es un indicativo de la riqueza de este campo de estudios en constante desarrollo y producción, por lo que la obra resulta de consulta necesaria para cualquier interesado en los procesos de violencia político-represiva en sus múltiples expresiones. 